\title{
COMMENTARY
}

\section{Growing the pool of rural general practitioners}

\section{AUTHORS}

Ronan F O'Toole ${ }^{1}$ BA(Mod), PhD, FASM, Associate Professor in Biomedical Sciences *

Julian Wright² BSc (Hons), MBBS, MSc, MD, FRACP, Head of Department, julian.wright@unimelb.edu.au

\section{CORRESPONDENCE}

*A/Prof Ronan F O'Toole r.otoole@latrobe.edu.au

\section{AFFILIATIONS}

${ }^{1}$ Department of Pharmacy and Biomedical Sciences, School of Molecular Sciences, College of Science, Health and Engineering, AlburyWodonga Campus, La Trobe University, Vic. 3690, Australia

2 Department of Rural Health, Melbourne Medical School, University of Melbourne, PO Box 6500, Shepparton, Vic. 3632, Australia

\section{PUBLISHED}

6 November 2020 Volume 20 Issue 4

HISTORY

RECEIVED: 5 December 2019

REVISED: 26 July 2020

ACCEPTED: 18 September 2020

\section{CITATION}

O'Toole RF, Wright J. Growing the pool of rural general practitioners. Rural and Remote Health 2020; 20: 5769. https://doi.org/10.22605 /RRH5769

\section{ETHICS APPROVAL}

\section{N/A}

This work is licensed under a Creative Commons Attribution 4.0 International Licence

\section{ABSTRACT:}

The critical importance of primary health care in maintaining a healthy population is well established internationally. Nevertheless, general practitioner care is not always easily accessible for some patients in Australia, particularly in rural regions. This is partly due to an insufficient number of medical graduates entering and being retained in the rural general practitioner workforce. Key elements of international and national programs designed to address this Keywords: shortfall are discussed and include the use of entry requirements that preferentially select for applicants from a rural residence background, and immersion of medical students for a large share, or entire duration, of their training in rural communities. In addition, other factors that can influence decisions to enter and stay in rural practice are discussed.

Australia, general practice, healthcare access, medical education, Modified Monash Model, rural health workforce. 


\section{Background}

Article 25 of the Universal Declaration of Human Rights, proclaimed by the UN in 1948, affirms that all individuals have the right to a standard of living that is adequate for the health and wellbeing of themselves and their families, including food, clothing, housing and medical care ${ }^{\mathbf{1}}$. Primary health care has long been identified as an essential component for safeguarding this human right. The Declaration of Alma-Ata, adopted at the International Conference on Primary Health Care in 1978, states that primary health care 'forms an integral part both of the country's health system, of which it is the central function and main focus, and of the overall social and economic development of the community'2.

Former Director-General of the World Health Organization, Halfdan Mahler, advocated in 1981 that 'health services must be accessible to all through primary health care, in which basic medical help is available in every village, backed up by referral services to more specialized care ${ }^{\prime \mathbf{3}}$. Inequalities in access to primary health care can lead to poorer health outcomes. For example, lack of continuity of primary care has been found to result in higher downstream hospital admissions for ambulatory care ${ }^{\mathbf{4}}$. A study from Canada found that factors that contributed to a shortage of physicians included past healthcare policies (such as retirement incentives and reduced medical school enrolments), shifts in population and physician demographics, medical student career preferences, a decline in direct patient care hours per physician and an uneven physician distribution ${ }^{5}$. While the recruitment of international medical graduates is often seen as a part solution to this problem, there are reports from Canada and the UK that recruitment of overseas medical graduates can lead to a shortage of doctors in source countries, including developing countries that have invested limited resources in the education and training of their doctors ${ }^{\mathbf{6 , 7}}$. This raises a moral and ethical question with regard to the active recruitment of international medical graduates to fill gaps in physician numbers in higher income countries.

In Australia, it is recognised that geographical disparities in access to health services are prevalent. According to the Australian Medical Association in November 2018, 'Australians living in rural and remote areas have poorer access to local health services and higher rates of morbidity and mortality than Australians living in metropolitan areas' ${ }^{\mathbf{8}}$. A maldistribution in the medical workforce is believed to play a role in perpetuating this health disadvantage in rural and remote Australia ${ }^{9}$. This includes the distribution of general practitioners (GPs) whereby the full-time service equivalent of GPs per 100000 population decreases from 103.5 in major cities to 81.4 in remote communities and 70.5 in very remote communities ${ }^{\mathbf{1 0}}$. Furthermore, of all clinician groups of the medical practitioner workforce in Australia in 2015, GPs had the highest proportion (40.5\%) that were aged 55 years or more ${ }^{\mathbf{1 1}}$. Here, we review measures that are being undertaken to increase the workforce of rural GPs in Australia and overseas. We discuss factors that, based on the available evidence, appear to promote higher levels of recruitment of medical graduates to rural locations, and provide examples of their incorporation into medical education.

\section{Rural immersion during medical education}

The first medical school in Australia was established at the University of Melbourne in $1862^{\mathbf{1 2}}$. Today, there are 21 universities in the country with medical schools offering 5- or 6-year undergraduate medical courses, or a 4-year graduate entry degree. There has been an apparent trend towards the latter structure over recent years with a Doctor of Medicine or equivalent graduate program $^{\mathbf{1 3}}$. Historically, medical education and training had been conducted predominantly in large population centres from which graduates emerged and entered an urban or rural workforce. Today, many Australian universities integrate rural immersion in their medical education programs, aided by an increase in the number of rural clinical schools (RCSs) attached to medical schools ${ }^{\mathbf{1 2}}$. Depending on the specific medical program, rural immersion in Australia can range from 1 year to the full duration of the course. A relationship between increased duration of rural immersion at Australian medical schools and subsequent rural internship has been recognised ${ }^{\mathbf{1 4}}$.

A study of 965 graduates from the Australian National University medical school from 2007 to 2017 reported that $24.6 \%(n=51 / 207)$ of extended rural placement graduates were working in Remoteness Areas (RA) 2-5 of the Australian Standard Geographical Classification (ASGC) system, compared to $9.3 \%$ of non-rural stream graduates $(n=66 / 708)^{\mathbf{1 5}}$. A relatively high proportion of students who trained entirely in a rural setting through James Cook University went on to undertake a rural internship (67\%, $n=194 / 292)$ compared to programs with a 1-year rural immersion period ${ }^{\mathbf{1 4}, \mathbf{1 6}}$. A recent cross-sectional study of 12 RCSs in Australia found that students who participated in extended RCS placement were 1.5 and 2.6 times more likely to practice in an area classified as rural under the ASGC and the Modified Monash Model, respectively, after controlling for rural background ${ }^{\mathbf{1 7}}$. A study by Wilkinson et al of 2414 graduates of Australian medical schools found that rural GPs were more likely to report having had rural undergraduate training at medical school (odds ratio $(\mathrm{OR})=1.61 ; 95 \%$ confidence interval $(\mathrm{Cl}): 1.32-1.95)$ or rural postgraduate training $(\mathrm{OR}=3.42 ; 95 \% \mathrm{Cl}: 2.39-4.89)$ than their urban GP counterparts ${ }^{\mathbf{1 8}}$.

A 2012 study from the University of Manitoba involving 1269 physicians who graduated between 1965 and 2000 reported that medical graduates who had part of their medical school education in a rural setting were more likely to practise in rural locations in Canada $(\mathrm{OR}=1.34 ; 95 \% \mathrm{Cl}: 1.09-1.75)^{\mathbf{1 9}}$. Furthermore, rural experience during residency training related significantly to a higher likelihood of rural practice. The investigators also identified a direct relationship between greater distance of the rural undergraduate medical education and residency training experience from an urban centre, Winnipeg, and an increased likelihood of rural practice ${ }^{\mathbf{1 9}}$. Of note, in the USA, a study from the University of Louisville found that rural immersion medical studies 
for urban-origin students led to a more positive outlook toward pursuing a career in a small town setting, even after a relatively short (8-week) rural surgical clerkship ${ }^{\mathbf{2 0}}$.

New Zealand's two medical schools, located the University of Otago and University of Auckland, operate a 6-year undergraduate medical course in which students can apply to undertake a 1-year rural medical immersion program for year 5 of their studies. From a survey in 2013 of graduates who underwent the rural immersion program at the University of Auckland, known as P\%u0169kawakawa, 62\% ( $n=28 / 45)$ of respondents were working in regional or rural hospitals as opposed to urban hospitals ${ }^{\mathbf{2 1}}$. A study of 733 University of Otago medical graduates reported that students who underwent its Rural Medical Immersion Programme (RMIP) in year 5 exhibited a more than two-fold higher propensity $(\mathrm{OR}=2.5 ; 95 \% \mathrm{Cl}: 1.4-4.5)$ to practise outside of a major urban centre in New Zealand compared to graduates with no rural training ${ }^{22}$. It is worth noting that the proportion of University of Otago medical students who undertake the RMIP has been reported to be below $10 \%^{\mathbf{2 3}}$. Nevertheless, medical students from the RMIP were found to report greater experience of patient examination and patient education skills, and similar levels of total clinical skills experience and confidence to traditional medical students ${ }^{24}$.

\section{Rural background for the selection of medical students}

A decision by an individual on geographical location postqualification is multi-factorial and other considerations besides rural immersion can have a bearing on this outcome. A systemic review in 2003 by Laven and Wilkinson of 12 studies conducted in the USA, Canada and Australia found that rural background and rural schooling both increased the likelihood of subsequent rural practice by approximately two-fold $\mathbf{2 5}^{\mathbf{2 5}}$. This is supported by the University of Manitoba study of 1269 physicians from 2012 which determined that medical graduates who had attended rural high schools were more likely to practise in rural locations in Canada than their urban counterparts $(\mathrm{OR}=1.57 ; 95 \% \mathrm{Cl} \text { : } 1.09-2.26)^{\mathbf{1 9}}$. The investigators noted the importance of a continuum of education from high school to the end of residency training as a predictor of rural medical practice. This is in agreement with earlier findings from the University of Western Ontario which reported that practising rural physicians were significantly more likely to have come from a rural background (34.9\% v 14.6\%), to have had undergraduate rural medical education (55.4\% v $35.2 \%)$, and to have undergone postgraduate rural training (38.8\% v 20.2\%) than urban physicians ${ }^{\mathbf{2 6}}$.

In Australia, a study of 508 medical graduates from the University of Western Australia determined that students from a rural background were nearly four times more likely to practise rurally than their urban-origin counterparts $(\mathrm{OR}=3.9 ; 95 \% \mathrm{Cl}: 2.1-7.2)^{\mathbf{2 7}}$. Similarly, based on longitudinal data from 448 students who entered the University of Sydney medical program in consecutive years from 2005 to 2007 (55\% of the total number of students, $n=812$, who enrolled in the program during 2005-2007), investigators reported that students from a rural background were significantly more likely to exhibit a preference for a rural future practice both at the start and at the end of their medical studies $\mathbf{2 8}$ It is worth noting, from the 2019 national data report of the Medical Deans Australia and New Zealand, which is based on the Medical Schools Outcome Database survey of final-year students in medical schools across Australia, that medical students from a rural background consistently expressed a higher interest in Indigenous health than their counterparts from non-rural backgrounds ${ }^{29}$. This indicates that an important parallel exists between intention to practise in a rural location and an interest in serving the health needs of Indigenous communities.

In New Zealand, the University of Otago applies a subcategory known as New Zealand Rural Origins while the University of Auckland runs a Rural Regional Admission Scheme for the selection of a proportion of students with a rural background into their respective medical programs. Graduates from the University of Otago with a rural background had an approximately two-fold higher likelihood (OR=2.1; $95 \% \mathrm{Cl}$ : $1.2-3.6)$ of practising outside a major urban centre in New Zealand compared to graduates with no rural background $\mathbf{2 2}^{\mathbf{2 2}}$. As in Australia, there are reports of an ongoing shortage of GPs in certain parts of New Zealand. The GP workforce is ageing, with the 2018 Workforce Survey by the Royal New Zealand College of General Practitioners indicating that $47 \%$ of New Zealand's current GP workforce, which has an average age of 50.3 years, intend to retire by $2028^{30}$. Proposals to address this include a graduate-entry medical school proposed by the University of Waikato and Waikato District Health Board ${ }^{\mathbf{3 1}}$, and a national interprofessional school of rural health proposed by the University of Otago, University of Auckland and Auckland University of Technology ${ }^{23}$. In April 2019, the New Zealand Minister of Health announced that he was requesting the New Zealand's Rural General Practice Network and College of General Practitioners, as well as health academics at the Universities of Otago and Auckland, to work together with district health boards to scope a first rural health training hub in New Zealand and report on how it could be rolled out to other locations ${ }^{32}$.

\section{Recent policy initiatives to strengthen GP numbers in rural Australia}

To address inequities in health status for people residing in rural, remote and regional areas, the Australian Government undertook the establishment of a network of university departments of rural health and RCSs to provide an academic framework for the training of health professionals including GPs to improve the distribution of the medical workforce ${ }^{33}$. In 2016, the University Departments of Rural Health Program, the Rural Clinical Training and Support Program, the Dental Training - Extended Rural Placements Program and the Northern Territory Medical Program were merged into the Rural Health Multidisciplinary Training (RHMT) Program. Today, the RHMT program funds a nationwide network of 19 RCSs, 16 university departments of rural health, and six dental schools to support rural placements for students in medicine, nursing, allied health and dentistry ${ }^{33}$. To build on the RHMT program network, the Australian Government announced in 2017 the establishment of 26 regional training hubs with objectives that included enabling students intending to practise rurally to complete as much of their medical training as possible in 
regional and rural areas, and developing greater regional clinical supervision capacity ${ }^{34}$.

Following on from these programs, the Australian Government, as part of its 2018-2019 federal budget, announced in May 2018 a $\$ 95.4$ million investment over 4 years in the Murray-Darling Medical Schools Network initiative, under its Stronger Rural Health Strategy ${ }^{35}$. The goal of the network is to provide end-to-end teaching and training of medical students in rural Victoria and New South Wales. The network consists of the following member institutes (and locations): University of New South Wales (Wagga Wagga), University of Sydney (Dubbo), Charles Sturt University/Western Sydney University (Orange), Monash University (Bendigo, Gippsland and Mildura) and University of Melbourne/La Trobe University (Shepparton, Bendigo and Albury-Wodonga). The La Trobe University and University of Melbourne partnership, which took in its first students in March 2019, commences with a 3-year undergraduate Bachelor of Biomedical Science (Medical) degree at the Bendigo or Albury-Wodonga campuses of La Trobe University, followed by a 4-year Doctor of Medicine (Rural Stream) degree at the Shepparton campus of the University of Melbourne. Therefore, students undergo all years of their pre-medical and medical study in an ASGC RA2. In addition, for selection into the program, applicants must have resided in an RA2 to RA5 area for a minimum number of years. Intakes into rural medicine at other institutes belonging to the Murray-Darling Medical Schools Network are due to follow in the coming years ${ }^{\mathbf{3 6}}$ and this should produce valuable data for the further optimisation of selection and rural immersion processes.

In its 2019-2020 federal budget, the Australian Government announced another measure, the Better Distribution of Medical Practitioners, to reduce the number of overseas-trained doctors granted visas to practise in well-serviced major capital cities under the Visas for GPs Program of the Skilled Migration Program ${ }^{37,38}$. Employers sponsoring an overseas doctor's application for a visa under the program will be required to obtain a Health Workforce Certificate from a rural workforce agency that assesses the position based on a number of criteria including GP catchment size, number of dedicated GPs and practices in the catchment, GP overcapacity, service complexity, level of socioeconomic disadvantage and the area's Modified Monash Model (MMM) classification with respect to rurality and remoteness ${ }^{37}$. This measure should better direct overseas-trained doctors to the so-called Distribution Priority Areas, which include areas in the Northern Territory, rural and remote areas classified under the MMM as MM 5 to MM 7, and other areas where the level of health services for the population does not meet a service benchmark ${ }^{39}$. However, this measure still draws on a pool of graduates who have been educated and trained overseas and, as outlined in an earlier section, this can lead to considerations with regard to the potential effect on doctor supply in source countries.

\section{Other considerations regarding rural practice preference}

It is becoming apparent from the international data that the inclusion of rural residence requirements in student selection processes, and the immersion of medical students for longitudinal training in rural locations, can positively influence the proportion of graduates who decide to enter rural general practice. But it is important to note that these influences may not necessarily contribute equally to a preference for rural practice. For example, in the longitudinal study of 448 students who entered the University of Sydney medical program from 2005 to 2007, the authors performed an analysis on students who undertook an extended rural placement $(n=98)$ versus students who selfidentified as having a rural background $(n=73)$. They reported that students who undertook an extended rural placement were more than three times as likely to express a rural internship first preference $(23.9 \% \vee 7.7 \%)$, and more than twice as likely to accept a rural internship $(21.3 \% \vee 9.9 \%)$ than students from a rural background in the same medical program ${ }^{\mathbf{2 8}}$. Therefore, in that particular study, rural immersion appeared to exhibit a higher impact than rural background on rural internship. More research with greater numbers of students in comparator groups is needed to ascertain whether these differences are observed across a number of medical programs over a longer period of time.

Several other factors in addition to rural immersion and background can influence decisions to practise rurally. The Western Australia study of 508 medical graduates found that the effect of immersion at a rural clinical school was statistically insignificant if there was no pre-existing intent to practise rurally $(\mathrm{OR}=1.38 ; 95 \% \mathrm{Cl}: 0.61-3.16 ; p=0.44)^{\mathbf{2 7}}$. Therefore, selection processes that detect the presence of strong rural intent are an essential early component in the acceptance of candidates into medical education programs that aim to produce doctors for rural and remote areas.

Financial factors also play a part in the location choices and mobility of GPs in Australia. Data from the Medicine in Australia: Balancing Employment and Life survey revealed that GPs, once established, are not particularly mobile. Older, self-employed GPs are less likely to relocate than younger and employee GPs, and general practice ownership played nearly as great a role as did earnings ${ }^{\mathbf{4 0}}$. While it is estimated that around $10 \%$ of Australian GPs change their principal place of practice annually, most of this movement is between major cities, with limited movement from major cities to rural and remote destinations ${ }^{\mathbf{4 1}}$. Therefore, once GPs become established in a city, it is relatively difficult for them to be recruited to rural and remote Australia.

It is worth noting that while there has been a moderate increase in final-year medical students in Australia expressing a preference for future practice outside of capital cities (from 30.1\% in 2014 to $35.8 \%$ in 2018), this has largely been driven by an increase in interest in practice in major urban centres and in regional cities or large towns. Interest has remained low regarding practice in smaller towns (3.2\% in 2014 and $4.1 \%$ in 2018) and small communities (1.4\% in 2014 and $1.3 \%$ in 2018) ${ }^{\mathbf{2 9}}$. Similar findings have been reported from an analysis of New Zealand medical students with regard to a low preference for intended practice in towns (10 000-24 999 population) and small towns (<10 000 population $)^{\mathbf{4 2 , 4 3}}$. Therefore, when addressing the shortage of rural GPs, it will be important to ensure that measures encompass smaller towns and communities in addition to large rural and 
regional centres, and that 'rural' is not treated as a single homogenous grouping. Of note, New Zealand's Health Research Council announced in June 2019 that it was funding a project to develop a consistent classification system for 'rural' and 'urban' in relation to health care, which should assist in clearer quantification of inequities in healthcare access and outcomes in rural New Zealand $\mathbf{4 4}^{\text {. }}$

The attractiveness of general practice on the whole is also an important factor in whether there will be a sufficient supply of medical graduates entering rural medical practice. In a study conducted by Hay et al, which examined 5862 Australian undergraduate medical students who commenced from 2006 to 2013 across nine medical schools, less than one-fifth of rural-origin students (17.6\%) and only $10.5 \%$ of urban-origin students indicated a preference for future generalist practice at course exit ${ }^{45}$. A significant predictor of a preference for general practice was female gender ( $\mathrm{OR}=1.7 ; 95 \% \mathrm{Cl}: 0.39-0.94 ; p<0.05)$. This is in agreement with an earlier longitudinal study in the UK by Sinclair et al, which also found that females were more likely to favour a career in general practice ${ }^{\mathbf{4 6}}$. In a study of 5688 medical students in Australia who graduated from 2008 to 2011, female gender was also associated with a preference for future general practice in a rural location $(\mathrm{OR}=1.24 ; 95 \% \mathrm{Cl} \text { : } 1.01-1.53 ; p<0.05)^{47}$. Reasons provided in the Sinclair et al study for a general practice preference included working in and being part of a community, continuity of patient contact, the range of illnesses and people encountered, undergraduate teaching experiences, dislike of hospital medicine and an awareness of lifestyle opportunities including the possibility of working part-time ${ }^{\mathbf{4 6}}$. Reasons given against a general practice career included that it was considered dull and routine; that it lacked variety, challenge and seriously ill patients compared to hospital medicine; and that it 'was seen by some as a waste of their undergraduate medical degree' ${ }^{\mathbf{4 6}}$. Adult Medicine/Internal Medicine/Physician has been the most preferred specialty of future practice for final-year medical students in Australia since 2014 (at 19.1\% in 2018) followed by Surgery $(15.5 \%$ in 2018) and General Practice (15.4\% in 2018) ${ }^{\mathbf{2 9}}$. As part of strategies to address a shortage in rural GPs, the broader reasons behind medical graduates choosing a career outside general practice must also be addressed.

While much of the emphasis to date has centred on attracting and recruiting doctors to rural areas to practice, there also needs to be a strong focus placed on providing the necessary conditions that encourage medical graduates to stay in rural regions after they have commenced their practice there. As reported recently by Cosgrave et al, there is an identified need to develop retention strategies for the rural health workforce that enhance rural familiarity and interest, social connectiveness, community participation and satisfaction, and the fulfilment of life aspirations including educational and clinical experiences as well as career progression $^{\mathbf{4 8}}$.

\section{Future perspectives and conclusions}

To address a number of the factors associated with the medical workforce shortage in rural areas, the Australian Medical
Association has proposed a set of solutions for the government to implement which are based on five key priority areas ${ }^{\mathbf{4 9}}$.

1. encourage students from rural areas to enroll in medical school and provide medical students with opportunities for positive and continuing exposure to regional/rural medical training;

2. provide a dedicated and quality training pathway with the right skill mix to ensure doctors are adequately trained to work in rural areas;

3. provide a rewarding and sustainable work environment with adequate facilities, professional support and education, personal comfort, and flexible work arrangements, including locum relief;

4. provide family support that includes spousal opportunities/employment, educational opportunities for children's education, subsidy for housing/relocation and/or tax relief; and

5. provide financial incentives including rural loadings to ensure competitive remuneration.

Measures that will assist in the achievement of these aims with respect to pre-vocational and vocational training of medical graduates in the rural setting include:

- expansion of the regional training hubs to support and mentor more rural junior doctors, rural generalists, specialist training posts in rural areas and Aboriginal medical trainees

- further emphasis on the creation of training pathways for rural generalists led by the National Rural Health Commissioner and investment in additional training positions

- future initiatives to grow specialist training outside metropolitan regions, such as selection of a quota of rural/regional trainees to college training posts, and innovative supervision models for junior doctors early in their specialist training, potentially involving partnerships between regional training hubs and RCSs to overcome insufficient numbers of specialists in regional and rural Australia to supervise trainees.

Adoption of these measures is key to strengthening the rural health system and improving health outcomes, but it will require substantial investment coupled with ongoing evaluation and enhancement of rural and remote training programs.

It is envisaged that the steps enacted by the government and medical schools in Australia to date will augment the recruitment of graduates to rural practice. However, a national longitudinal study that examines and quantifies each of the variables that affect entry into rural general practice, while controlling for confounding factors, is needed. This will guide further measures to attract higher numbers of medical graduates into rural general practice. Initiatives are also required to optimise the retention and career development of GPs in rural communities. The experiences and findings from Australia will likely assist efforts in other countries to ensure that access to primary health care is an exercisable right for all, including populations in rural and remote regions. This should 
bring more countries closer to a realisation of the goals of the UN's Universal Declaration of Human Rights and the Declaration of
Alma-Ata in relation to primary health care and human health.

\section{REFERENCES:}

1 United Nations. Universal Declaration of Human Rights. Paris: United Nations General Assembly, 1948.

2 World Health Organization. Declaration of Alma-Ata. Almaty, Kazakhstan. International Conference on Primary Health Care, 6-12 September, 1978.

3 Brown TM. The meaning of 'Health for All by the Year 2000'. American Journal of Public Health 2016; 106(1): 36-38.

4 Barker I, Steventon A, Deeny SR. Association between continuity of care in general practice and hospital admissions for ambulatory care sensitive conditions: cross sectional study of routinely collected, person level data. British Medical Journal 2017; 356: j84. https://doi.org/10.1136/bmj.j84 PMid:28148478

5 Malko AV, Huckfeldt V. Physician shortage in Canada: a review of contributing factors. Global Journal of Health Science 2017; 9(9): 68-80. https://doi.org/10.5539/gjhs.v9n9p68

6 Islam N. The dilemma of physician shortage and international recruitment in Canada. International Journal of Health Policy Management 2014; 3(1): 29-32. https://doi.org/10.15171 /ijhpm.2014.53 PMid:24987719

7 Rimmer A. Shortage of doctors across Europe may be caused by migration to UK. British Medical Journal 2014; 349: g5874. https://doi.org/10.1136/bmj.g5874

8 Australian Institute of Health and Welfare. Australia's Health 2016. Canberra: Australian Institute of Health and Welfare, 2017.

9 National Rural Generalist Taskforce. National Rural Generalist Taskforce advice to the National Rural Health Commissioner on the development of the National Rural Generalist Pathway. 2018. Adelaide: National Rural Generalist Taskforce.

10 Royal Australian College of General Practitioners. General Practice: Health of the Nation. Melbourne: Royal Australian College of General Practitioners, 2019.

11 Australian Institute of Health and Welfare. Medical Practitioners Workforce 2015. Canberra: Australian Institute of Health and Welfare, 2017.

12 Geffen L. A brief history of medical education and training in Australia. Medical Journal of Australia 2014; 201(1 Suppl): S19S22. https://doi.org/10.5694/mja14.00118 PMid:25047770

13 Department of Health. Medical Training Review Panel 19th report. Canberra: Commonwealth of Australia, 2016.

14 O'Sullivan BG, McGrail MR, Russell D, Chambers H, Major L. A review of characteristics and outcomes of Australia's undergraduate medical education rural immersion programs. Human Resources for Health 2018; 16(1): 8. https://doi.org/10.1186 /s12960-018-0271-2 PMid:29386024

15 Moore M, Burgis-Kasthala S, Barnard A, Hall S, Marks S. Rural clinical school students do come back: but it may take time. Australian Journal of General Practice 2018; 47(11): 1-5.
https://doi.org/10.31128/AJGP-02-18-4505 PMid:31207682

16 Sen Gupta T, Murray R, Hays R, Woolley T. James Cook University MBBS graduate intentions and intern destinations: a comparative study with other Queensland and Australian medical schools. Rural and Remote Health 2013; 13(2): 2313. Available: http://www.rrh.org.au/journal/article/2313 (Accessed 27 June 2019). https://doi.org/10.22605/RRH2313 PMid:23751066

17 McGirr J, Seal A, Barnard A, Cheek C, Garne D, Greenhill J, et al. The Australian Rural Clinical School (RCS) program supports rural medical workforce: evidence from a cross-sectional study of 12 RCSs. Rural and Remote Health 2019; 19(1): 4971. Available: http://www.rrh.org.au/journal/article/4971 (Accessed 4 December 2019). https://doi.org/10.22605/RRH4971 PMid:30827118

18 Wilkinson D, Laven G, Pratt N, Beilby J. Impact of undergraduate and postgraduate rural training, and medical school entry criteria on rural practice among Australian general practitioners: national study of 2414 doctors. Medical Education 2003; 37(9): 809-814. https://doi.org/10.1046 /j.1365-2923.2003.01596.x PMid:12950945

19 Tate RB, Aoki FY. Rural practice and the personal and educational characteristics of medical students: survey of 1269 graduates of the University of Manitoba. Canadian Family Physician 2012; 58(11): e641-e648.

20 Crump AM, Jeter K, Mullins S, Shadoan A, Ziegler C, Crump WJ. Rural medicine realities: the impact of immersion on urban-based medical students. Journal of Rural Health 2019; 35(1): 42-48. https://doi.org/10.1111/jrh.12244 PMid:28464267

21 Matthews C, Bagg W, Yielder J, Mogol V, Poole P. Does Pukawakawa (the regional-rural programme at the University of Auckland) influence workforce choice? New Zealand Medical Journal 2015; 128(1409): 35-43.

22 Shelker W, Zaharic T, Sijnja B, Glue P. Influence of rural background and rural medical training on postgraduate medical training and location in New Zealand. New Zealand Medical Journal 2014; 127(1403): 12-16.

23 Nixon GH, Kerse NM, Bagg W, Skinner MA, Larmer PJ, Crampton P. Proposal for a National Interprofessional School of Rural Health. New Zealand Medical Journal 2018; 131(1485): 67-75.

24 Rudland J, Tordoff R, Reid J, Farry P. The clinical skills experience of rural immersion medical students and traditional hospital placement students: a student perspective. Medical Teacher 2011; 33(8): e435-e439. https://doi.org/10.3109/0142159X.2011.586745 PMid:21774640

25 Laven G, Wilkinson D. Rural doctors and rural backgrounds: how strong is the evidence? A systematic review. Australian Journal of Rural Health 2003; 11(6): 277-284. https://doi.org/10.1111 /j.1440-1584.2003.00534.x PMid:14678410 
26 Rourke JT, Incitti F, Rourke LL, Kennard M. Relationship between practice location of Ontario family physicians and their rural background or amount of rural medical education experience. Canadian Journal of Rural Medicine 2005; 10(4): 231-240.

27 Playford D, Ngo H, Gupta S, Puddey IB. Opting for rural practice: the influence of medical student origin, intention and immersion experience. Medical Journal of Australia 2017; 207(4): 154-158. https://doi.org/10.5694/mja16.01322 PMid:28814216

28 Clark TR, Freedman SB, Croft AJ, Dalton HE, Luscombe GM, Brown AM, et al. Medical graduates becoming rural doctors: rural background versus extended rural placement. Medical Journal Australia 2013; 199(11): 779-782. https://doi.org/10.5694 /mja13.10036 PMid:24329657

29 Medical Deans Australia and New Zealand. Medical Schools Outcomes Database - National Data Report. Sydney: Medical Deans Australia and New Zealand, 2019.

30 Royal New Zealand College of General Practitioners. 2018 Workforce Survey. Wellington: Royal New Zealand College of General Practitioners, 2018.

31 The University of Waikato and Waikato District Health Board. A community-engaged graduate entry medical school: the case for a third medical school in New Zealand. Hamilton: University of Waikato, 2017.

32 Clark D. Minister of Health address. Blenheim: National Rural Health Conference., 2019.

33 KBC Australia. Evaluation of the Rural Health Multidisciplinary Training Program. Orange, NSW: KBC Australia, 2019.

34 Department of Health. Regional Training Hubs. Canberra: Commonwealth Government, 2017.

35 Department of Health. Stronger Rural Health Strategy - The Murray-Darling Medical Schools Network. 2018. Available: https://www1.health.gov.au/internet/main/publishing.nsf/Content /stronger-rural-health-strategy-the-murray-darling-medicalschools-network (Accessed 7 December 2018).

36 UNSW Media. Federal funding boost for UNSW Rural Clinical School. 2018. Available: https://newsroom.unsw.edu.au /news/health/federal-funding-boost-unsw-rural-clinical-school (Accessed 20 December 2018).

37 Department of Health. Visas for GPs: targeting areas of doctor shortages. 2019. Available: https://www.health.gov.au/resources /publications/visas-for-gps-targeting-areas-of-doctor-shortagesprogram-guidelines (Accessed 4 December 2019).

38 Department of Health. Directing doctors to areas of greatest need. 2019. Available: https://www.health.gov.au/resources /publications/directing-doctors-to-areas-of-greatest-need (Accessed 4 December 2019).

39 Department of Health. Distribution priority area. 2019. Available: https://www.health.gov.au/health-workforce/health-workforceclassifications/distribution-priority-area (Accessed 4 December 2019).

40 Mclsaac M, Scott A, Kalb G. The role of financial factors in the mobility and location choices of general practitioners in Australia. Human Resources for Health 2019; 17(1): 34. https://doi.org /10.1186/s12960-019-0374-4 PMid:31126294

41 Mazumdar S, McRae I. Doctors on the move: national estimates of geographical mobility among general practitioners in Australia. Australian Family Physician 2015; 44(10): 747-751.

42 Poole P, Wilkinson TJ, Bagg W, Freegard J, Hyland F, Jo CE, et al. Developing New Zealand's medical workforce: realising the potential of longitudinal career tracking. New Zealand Medical Journal 2019; 132(1495): 65-73.

43 Nixon G, Blattner K, Miller R, Bolden F, Jelley G, Keys J. Few New Zealand medical students intend to work in rural areas. New Zealand Medical Journal 2019; 132(1498): 105-106.

44 Nixon G. A rural-urban classification for New Zealand health research and policy. Auckland: Health Research Council of New Zealand, 2019

45 Hay M, Mercer AM, Lichtwark I, Tran S, Hodgson WC, Aretz HT, et al. Selecting for a sustainable workforce to meet the future healthcare needs of rural communities in Australia. Advances in Health Sciences Education Theory and Practice 2017; 22(2): 533-551. https://doi.org/10.1007/s10459-016-9727-0 PMid:27804091

46 Sinclair HK, Ritchie LD, Lee AJ. A future career in general practice? A longitudinal study of medical students and preregistration house officers. European Journal of General Practice 2006; 12(3): 120-127. https://doi.org/10.1080 /13814780600780833 PMid:17002960

47 Hays RB, Lockhart KR, Teo E, Smith J, Waynforth D. Full medical program fees and medical student career intention. Medical Journal of Australia 2015; 202(1): 46-49. https://doi.org/10.5694 /mja14.00454 PMid:25588446

48 Cosgrave C, Malatzky C, Gillespie J. Social determinants of rural health workforce retention: a scoping review. International Journal of Environmental Research and Public Health 2019; 16(3): 314. https://doi.org/10.3390/ijerph16030314 PMid:30678350

49 Australian Medical Association. AMA Position Statement - Rural Workforce Initiatives. Canberra: Australian Medical Association, 2017.

This PDF has been produced for your convenience. Always refer to the live site https://www.rrh.org.au/journal/article/5769 for the Version of Record. 